\title{
Correlation of Infrared Optical Lens and Infrared Glass Materials
}

\author{
Choi Ju Hyeon ${ }^{\dagger}$
}

Korea Photonics Technology Institute, Gwangju, 61007, Republic of Korea

\section{적외선 광학렌즈와 칼코지나이드 기반 광학유리의 상관 관계}

\author{
최주현 ${ }^{\dagger}$ \\ 한국광기술원
}

(Received August 27, 2020; Revised September 10, 2020; Accepted September 11, 2020)

\begin{abstract}
Infrared optical glass properties such as refractive index and dispersion value are key factors in designing infrared optical lenses. Until now, infrared optical lenses successfully have been developed using chalcogenide glass materials such as Ge, As, Sb, S, and Se elements. Trends using corelation between dispersion and abbe number was described using standard Abbe diagrams for broad band spectrum. However, it was reported that dramatic changes to Abbe diagram depending on which band is examined. In this report, newly developed chalcogenide optical glass with low or high dispersion was applied to a new diagram. The effect was investigated by selecting two infrared optical materials that can reduce chromatic Abberations when designing an chromatic lens. It was found that chalcogenide glasses tended to suppress chromatic abberations in comparing with commercial crystal materials, such as ZnSe, ZnS used.
\end{abstract}

Keywords: Infrared Optical Glass, Infrared Optical Lens

${ }^{\dagger}$ Corresponding Author: Ju Hyeon Choi

E-mail: juchoi2@kopti.re.kr 


\section{1. 서론}

적외선은 전자기파 스펙트럼에서 가시광선과 마이크 로파 사이에 있는 광선이며, 온도가 있는 물체, 즉 열을 가진 물체는 그 열을 적외선으로 방출하며 이를 영상화 하는 것이 적외선 열영상 카메라이다. 사람의 눈에 보 이는 것은 가시광 파장대의 광선뿐이며, 적외선은 전자 기파 스펙트럼에서 가시광선과 마이크로파 사이에 있는 광선으로 절대온도 $\left(-273.15^{\circ} \mathrm{C}\right.$ 또는 $\left.0 \mathrm{~K}\right)$ 이상의 온도를 가지는 모든 물체는 적외선 영역의 광선을 복사한다, 물 체의 온도가 높을수록 더 많은 적외선이 방출되는 특성

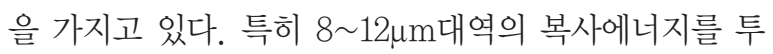
과하는 광학소재를 적외선 광학소재라 칭하며 결정질의 경우 $\mathrm{Ge}, \mathrm{ZnSe}, \mathrm{ZnS}$, 등이 있고 대표적으로 비정질 소 재는 $\mathrm{Ge}, \mathrm{As}, \mathrm{Sb}, \mathrm{S}, \mathrm{Se}$ 칼코겐 원소를 포함한 칼코지 나이드 유리이다.

적외선 열화상 카메라는 군수용으로 개발되어 중적외 선, 원적외선 모든 파장대역을 사용하였고 상대적으로 결정질 기반의 적외선 광학소재를 적용 하여 직가공 방 식으로 비구면 렌즈를 제작하여 적용하였다. ${ }^{1)}$

민수에서 보급형 열화상 카메라의 필요성이 대두되었 으며 대량생산이 용이하고 저가격에 대량생산이 가능한 칼코지나이드 광학유리소재 및 광학렌즈의 활용성이 크 게 관심을 끌었다. ${ }^{2}$ 몰드성형 칼코지나이드 렌즈를 적 용한 열화상 카메라는 가정용에서 산업용에 이르기까지 다양한 범위로 확대되고 있다. ${ }^{3)}$ 특히 저화소급(80x80, $160 \times 120,320 \times 240)$ 적외선 이미지 센서 보급이 확대 되어감에 따라 체온측정용 카메라, 자율주행차용 나이 트비젼 카메라, 보안감시 카메라, 등 새로운 시장이 형 성되고 있다.

400여 조성이 개발된 가시광 광학유리소재와 달리 칼 코지나이드 기반 상용 원적외선 광학유리소재는 10 여종 에 불과하다. 광학소재의 다양성이 부족하다는 것은 광 학렌즈 설계 시 광학 특성 및 디자인 요소 도출이 상대 적으로 제약이 있다는 의미로 해석될 수 있다. 다양한 조성에 따른 굴절률과 분산 변화에 관한연구 및 몰드성 형 전후의 굴절률 변화 연구등이 보고된 봐 있다. ${ }^{4,5)}$ 본
연구에서는 칼코지나이드 유리소재의 렌즈 디자인에 필 요한 광학적 요소 도출, 저분산 소재와 고분산 소재의 조성 개발의 필요성 및 이를 적용한 광학렌즈 적용성에 대해 소개하고자 한다.

\section{2. 본론}

\section{1. 칼코지나이드 광학유리}

칼코지나이드 유리소재의 경우 $\mathrm{Ge}, \mathrm{As}, \mathrm{Sb}, \mathrm{S}, \mathrm{Se}$ 칼 코겐 원소를 포함하고 있으며 다양한 첨가물에 의한 특 성을 가진 원적외선 투과도를 가지는 유리소재이다. 대 부분의 비 광학적 특성은 조정 및 결합 에너지에서 결정 할 수 있다. 공유 상관 계수로 살펴보면 $\mathrm{Ge}(4), \mathrm{As}(3)$, $\mathrm{Sb}(3), \mathrm{S}(2), \mathrm{Se}(2)$ 를 가지고 있으며 산화물 유리에서 는 존재할 수 없는 결합(예 : $\mathrm{Si}-\mathrm{Si}$ 또는 $\mathrm{O}-\mathrm{O}$ )으로 간 주될 수 있는 Homo-bonding, Hetero-bonding 등이 칼코지나이드 유리에서는 일반적으로 존재할 수 있다. 상용소재 가운데 가장 많이 사용되고 있는 $\mathrm{Ge}-\mathrm{Sb}-\mathrm{Se}$ (IRG25 $=\mathrm{Ge}_{28} \mathrm{Sb}_{12} \mathrm{Se}_{60}$, 유리가 100 개의 원자로 구성되 었다고 가정할 때 $\mathrm{Ge}-\mathrm{Se}$ 결합 수 98 개, $\mathrm{Sb}-\mathrm{Se}$ 결합 수 22 개, $\mathrm{Ge}-\mathrm{Sb}$ 결합 수 14 개 형성). 구성될 수 있으나 대 부분의 비 광학적 특성은 조정 및 결합 에너지에서 결정 할 수 있다. 하지만 일반적인 물리적 특성 등은 속성 간 의 일반적인 상쇄효과가 있으므로 유리조성 설계 및 렌 즈에서의 특성은 매우 다양하다.

현재 상용소재로는 Schott AG, VITRON (독)을 포함 하여 8개 해외 선진사기업에서 생산하고 있으며 조성 측 면에서는 분산값이 상대적으로 높은 As을 포함한 저분 산 조성이 주를 이루고 있다. 하지만 민수시장에서는 As 등이 포함되지 않은 조성을 사용한 적외선 광학렌즈가 필요하므로 $\mathrm{Ge}-\mathrm{Sb}-\mathrm{Se}$ 기반의 상용 조성이 가장 많이 사용되고 있다.

조성 측면에서 일반적인 물성동향을 살펴보면 열적특 성의 대표적인 유리전이온도와 $(\mathrm{Tg})$ 과 열기계적 특성인 열팽창계수(CTE)는 상호 밀접하게 연결되어 있다. 더 강한 화학결합과 더 많은 결합은 높은 $\mathrm{Tg}$ 와 경도 및 낮 은 $\mathrm{CTE}$ 를 생성한다. $\mathrm{Ge}$ 는 가장 높은 결합 수와 가장 강 
Table 1. 상용 칼코지나이드 유리소재 대표 조성 및 모델

\begin{tabular}{|c|c|c|c|c|c|c|c|c|c|}
\hline$\#$ & Compositions & AMI & SCHOTT & VITRON & Umicore & $\mathrm{RPO}$ & LightPath & IRradiance & ISUZU \\
\hline 1 & $\mathrm{Ge}_{10} \mathrm{As}_{40} \mathrm{Se}_{50}$ & & IRG 24 & IG 4 & & & & CLASSIC 4 & \\
\hline 2 & $\mathrm{Ge}_{20} \mathrm{As}_{13} \mathrm{Se}_{65}$ & & & & GASIRR2 & & & & \\
\hline 3 & $\mathrm{Ge}_{22} \mathrm{As}_{20} \mathrm{Se}_{58}$ & & & & GASIR $(1$ & & & & \\
\hline 4 & $\mathrm{Ge}_{33} \mathrm{As}_{12} \mathrm{Se}_{55}$ & AMTIR-1 & IRG 22 & IG 2 & & OPTIR-1 & & CLASSIC 2 & \\
\hline 5 & $\mathrm{As}_{28} \mathrm{Se}_{72}$ & AMTIR-4 & & & & & & & \\
\hline 6 & $\mathrm{As}_{40} \mathrm{Se}_{60}$ & AMTIR-2 & IRG 26 & IG 6 & GASIR $(5$ & & $\mathrm{BD}-6$ & CLASSIC 6 & \\
\hline 7 & $\mathrm{As}-\mathrm{Se}^{*}$ & AMTIR-7 & & & & & & & \\
\hline 8 & $\mathrm{Ge}_{28} \mathrm{Sb}_{12} \mathrm{Se}_{60}$ & AMTIR-3 & IRG 25 & IG 5 & & OPTIR-2 & $\mathrm{BD}-2$ & CLASSIC 5 & \\
\hline 9 & $\mathrm{As}_{34} \mathrm{~S}_{66}$ & AMTIR-5 & & & & & & & \\
\hline 10 & $\mathrm{As}_{40} \mathrm{~S}_{60}$ & AMTIR-6 & IRG 27 & & & & & CLASSIC 1 & \\
\hline 11 & $\mathrm{Ge}_{30} \mathrm{Sb}_{13} \mathrm{Se}_{32} \mathrm{Te}_{25}$ & & & IG 3 & & & & CLASSIC 3 & \\
\hline 12 & $\mathrm{Ge}_{12} \mathrm{Sb}_{13} \mathrm{Sn}_{7} \mathrm{Se}_{68}$ & & & & GASIR $R 3$ & & & & \\
\hline 13 & $\mathrm{Ge}_{5} \mathrm{Sb}_{30} \mathrm{Sn}_{5} \mathrm{Se}_{60}$ & & & & & & & & IIR \\
\hline
\end{tabular}

한 결합 에너지를 가지고 있다 (평균 $320 \mathrm{kCal} / \mathrm{mol}$ ). $\mathrm{Sb}$ 는 결합 수가 가장 적고 결합이 가장 약하다 (평균 $216 \mathrm{kCal} / \mathrm{mol}$ ). 광학적 특성가운데 대표적인 분산값 은 화학 결합의 강도를 통해 금속의 정체성과 연결된다. 높은 결합 강도는 높은 포논 에너지를 나타내며 이것을 통해 높은 IR 분산값을 가지며 분산은 칼코겐 원자의 종 류 및 함량과 관련이 있다. 예를 들어 $\mathrm{S} \rightarrow \mathrm{Se} \rightarrow \mathrm{Te}$ 의 순 으로 원소 함량이 증가할 경우 더 낮은 분산을 나타내 며 또한 더 낮은 경도, 더 높은 CTE 등의 일반적인 경향 을 나타낸다. 하지만 상대적으로는 열적, 기계적 특성은 저하되는 경향이 있다. 온도에 따른 굴절률 변화와 같은 열광학 특성 $(\mathrm{dn} / \mathrm{dT})$ 는 분산 및 CTE에 의해 주요하게 결정된다. 높은 분산의 경우 상대적으로 높은 $\mathrm{dn} / \mathrm{dT}$ 를 나타낸다. 즉 열에 의한 밴드 갭 시프트가 일어나며, 높 은 CTE의 조성의 경우 낮은 $\mathrm{dn} / \mathrm{dT}$ 를 나타내므로 이는 열팽창은 온도가 증가함에 따라 밀도를 감소시키기 때 문이다. 따라서 낮은 $\mathrm{dn} / \mathrm{dT}$ 유리는 높은 CTE, 낮은 분 산, 낮은 경도의 경향성을 가지게 된다. 반대로 높은 경 도는 상대적으로 많은 수의 강한 결합을 필요로 하여 낮 은 CTE와 높은 분산의 경향을 가지게 된다.

적외선 광학렌즈를 설계 시 광학소재의 광학인자를 사용하여 디자인 되어진다. 가장 핵심기술로는 광학 수 차를 보정하기 위해 다양한 적외선 광학소재가 필요하
다. 광학설계 관면에서 수차가 발생하는 원인을 살펴 보면 첫번째로 구면 곡선은 구면 수차를 생성한다. 양 의 구면 수차는 다른 렌즈 표면의 음의 구면 수차에 의 해 균형을 이룰 수 있으며 Coma, Astigmatism 경우에 서도 동일한 효과가 있다. 각 개별렌즈 자유표면에 대해 서도 하나의 수차 보정을 가능하게 할 수 있다. 두 번째 로 색수차는 더 짧거나 더 긴 파장의 초점을 흐리게 된 다. 광학 재료의 경우 굴절률은 분산 함수로 표현할 수 있다. 광학소재를 적용하여 광학렌즈 설계 시 렌즈 파워 $(\varphi)$ 와 분산 $(\mathrm{v})$ 의 곱의 합은 0 이어야 한다. 즉 다시 말하 면 굴절률과 분산이 다른 렌즈의 포지티브 및 네거티브 요소와 더불어 상쇄 효과가 필요하다. 세 번째로 중요 한 요소는 열 광학 효과로 인해 온도 변화에 따라 수차 가 발생하게 된다. 온도에 따른 굴절률의 변화는 적외선 영역에서 열 효과의 균형을 맞추는 데 사용되는 색채 효 과를 수정하는 유사한 기술이지만 굴절률(n) 및 분산값 (v) 대신 열팽창계수(CTE) 및 온도에 따른 굴절률의 변 화 $(\mathrm{dn} / \mathrm{dT})$ 를 사용한다.

\section{2. 고분산, 저분산 칼코지나이드 유리}

현재 해외 선진사에서 상용으로 판매되고 있는 칼코 지나이드 유리소재와 한국광기술원에서 개발한 칼코지 나이드 유리소재의 굴절률과 분산값 분포를 아래 Fig. 1 


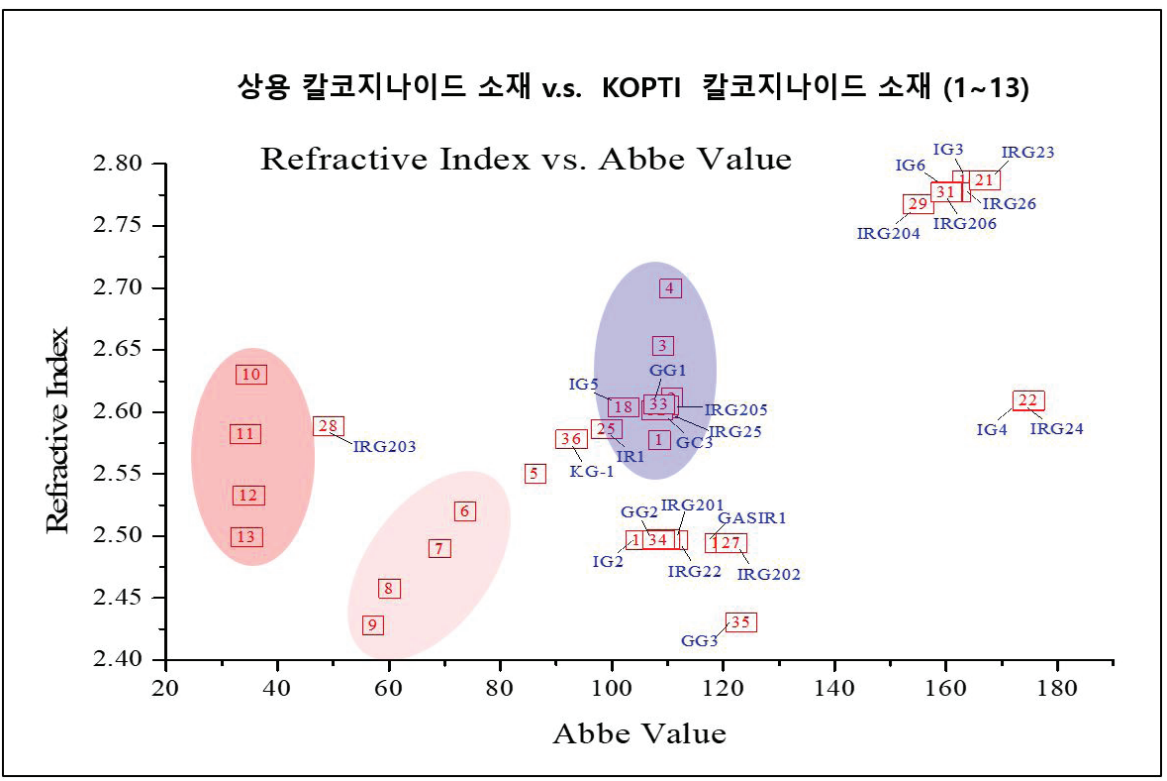

Fig. 1. Commercial chalcogenide glass and KOPTI chalcogenide glass

에서 나타내었다. $\mathrm{Ge}-\mathrm{Sb}-\mathrm{Se}$ 기반의 분산값 100 이상 굴절률 2.55 이상 4 종을 개발하였으며 $\mathrm{Ge}-\mathrm{Sb}-\mathrm{Se}$ 기반 조성에 $\mathrm{S}$ 을 첨가함에 따라 분산값의 조절 통한 고분산 조성 9종을 개발하였다.

본 연구에서는 저분산성, 고분산성 두 가지 조성을 준 비하였다. 320x240급 $34 \mu \mathrm{m}$ 열상 카메라에 사용되는 렌 즈 직경의 경우 $20 \mathrm{~mm}$ 내외의 규격을 채용하고 있으며 특히 굴절률 측정을 위한 프리즘 제작을 위해 직경 35 $\mathrm{mm}$ 칼코겐유리 잉곳을 제조하였다. 먼저 조성 몰비에 따른 원소재를 칙량하여 진공실링된 석영관에 장입 후 락킹하면서 $1000^{\circ} \mathrm{C}$ 에서 12 시간 유지하였다. $1000^{\circ} \mathrm{C}$ 에서 용융된 석영관을 이동하여 $270^{\circ} \mathrm{C}$ 로 예열된 전기로에서 3 시간동안 서냉공정을 거친 후 상온으로 냉각하였다.

Fig. 2는 최적 조건이라 판단되는 냉각조건으로 제작 된 저분산 칼코겐유리의 기본 특성인 투과율 및 굴절율 측정 결과를 나타낸 것이다. 총 13 종 개발 소재 가운데 유리안정성과 몰드성형성이 뛰어난 LD10과 HD10 조성 에 대하여 $2 \mathrm{~mm}$ 디스크를 제작하였다. 8 $12 \mu \mathrm{m}$ 평균 투과율은 저분산 LD10 조성의 경우 $62.9 \%$, 고분산 조 성인 HD10의 경우 58.3\%를 나타내었다 (Fig. 2 (a)). 칼코지나이드 유리의 분산값은 $\left(\mathrm{n}_{10 \mu \mathrm{m}}-1\right) /\left(\mathrm{n}_{8 \mu \mathrm{m}}-\mathrm{n}_{12 \mu \mathrm{m}}\right)$
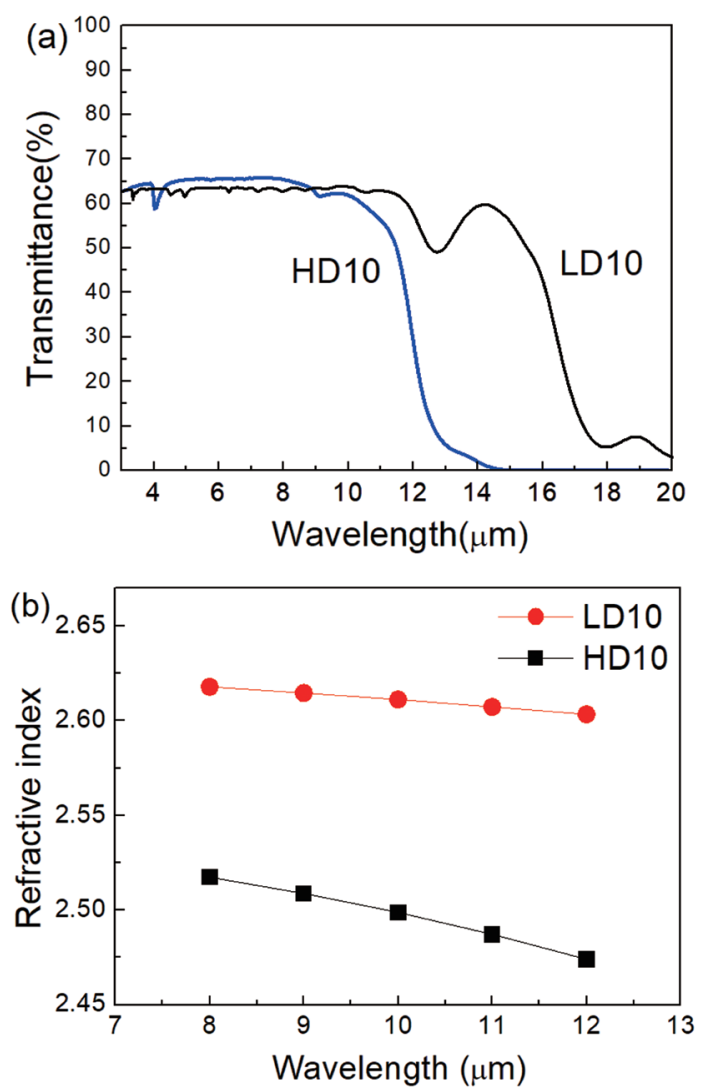

Fig. 2. (a) Transmittance and (b) refractive index on high(HD10) and low(LD10) dispersion chalcogenide glass 


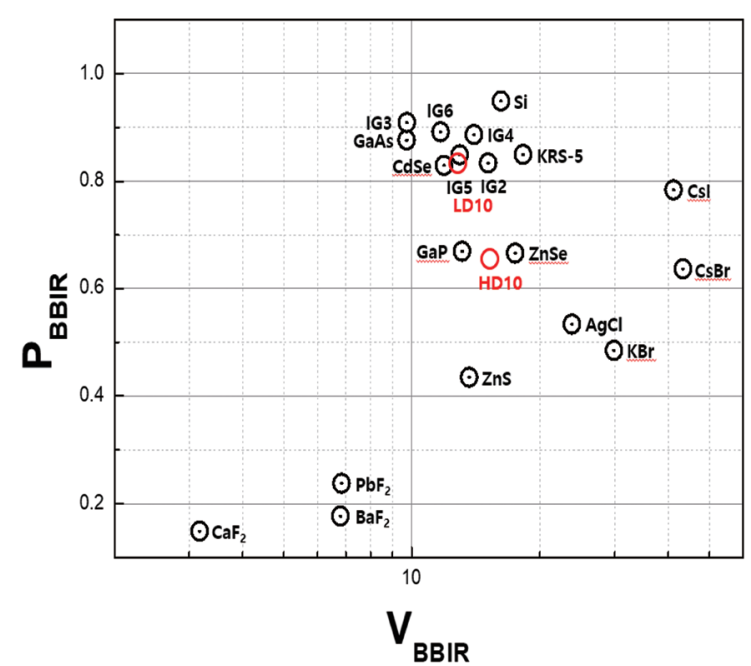

Fig. 3. Correlation between Broadband dispersion $\left(\mathrm{V}_{\mathrm{BBI}}\right)$ and Partial dispersion $\left(\mathrm{P}_{\mathrm{BB}}\right)$

식을 이용하여 산출할 수 있으며, 후보 조성인 LD10과 $\mathrm{HD} 10$ 유리 샘플의 굴절률을 측정하고 분산값을 산출하 였다. 후보 조성인 LD10과 HD10의 굴절률(@10um)은 각각 $2.6112,2.5822$ 를 나타내는 것이 확인되었으며, $\mathrm{LD} 10$ 의 경우 109.28 의 분산을 나타내어 저분산 특성을 지니는 유리 시편임을 확인하였다. 반면, $\mathrm{Se}$ 를 $\mathrm{S}$ 로 치환 한 $\mathrm{HD} 10$ 의 경우 34.52 의 분산을 가짐을 확인하여 고분 산 특성을 지니는 유리 시편임이 확인되었다.

\section{3. 칼코지나이드 적외선광학유리 기반 광학렌즈}

1880대에 이르러 Ernst Abbe와 Otto Schott는 유리 소재의 굴절률 분산과 이의 partial 분산 간의 선형관계 를 발견하였으며, 서로 다른 partial 분산을 가지는 유리 소재의 조합을 통해 개선된 결상 특성을 얻을 수 있음을 확인하였다. Fig. 3에는 수식 1과 2로 정의 되는 적외선 렌즈용 상용 소재의 전반적인 적외선 파장 대역에서의 굴절률 분산과 이의 partial 분산의 관계를 도시하였다. 본 연구소의 연구 결과를 통해 확보된 렌즈 소재의 분산 및 partial 분산은 상용 소재의 범위에서 크게 벗어나지 않음을 확인할 수 있다.

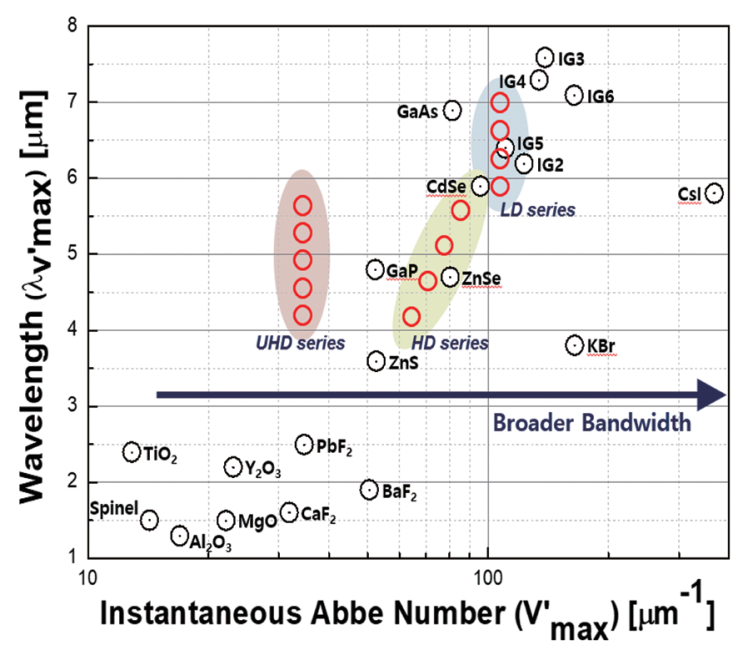

Fig. 4. Correlation between instantaneous Abbe number and wavelength

$$
\begin{aligned}
& V_{B B I R}=\frac{n_{5}-1}{n_{1}-n_{9}} \ldots \ldots \ldots \ldots \ldots \ldots \ldots \ldots \ldots \ldots \text { 식 } 1
\end{aligned}
$$

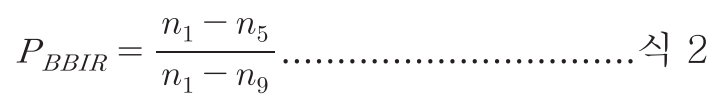

하지만, 이들은 실질적으로 적용되는 적외선 파장의 범위에 따라 상이한 굴절률 분산과 partial 분산 결과를 나타내어 결상 특성 개선을 위한 렌즈 소재의 조합에 혼 선을 야기한다. 이는 굴절률의 파장에 대한 굴절률 변화 가 소재에 따라 다르기 때문에 발생되는 현상으로서, 결 상 특성 개선을 위해 서로 다른 분산 특성을 가지는 소 재 선정 시 고려되어야 할 분산 특성 도출에 대한 추가 적인 개선이 요구되는 사항이다.

따라서, Sellmeier 수식 ${ }^{6)}$ 을 (식3) 도입하여 instantaneous 분산을 (식4) 도출함으로서 파장에 따른 분산의 영향을 최소화 한다면, 소재 간의 광학 특성 추 세가 보다 명확해지며, 재료에 기초한 광학 설계가 가능 해진다는 장점이 있다.

$$
\begin{array}{r}
n^{2}-1=\frac{B_{1} \lambda^{2}}{\lambda^{2}-C_{1}}+\frac{B_{2} \lambda^{2}}{\lambda^{2}-C_{2}}+\frac{B_{3} \lambda^{2}}{\lambda^{2}-C_{3}} \ldots . . . \text { 식 } 3 \\
\nu=\frac{d n}{d \lambda}=n^{-1} \sum_{i} \frac{-B_{i} C_{i} \lambda}{\left(\lambda-C_{i}\right)^{2}} \ldots \ldots . . . \text { 식 } 4
\end{array}
$$


그러나, 광학 설계 시 소재의 분산값의 차이를 통한 설계와 비교하여 소재 간의 Abbe number 차이를 이용 한 설계 보다 유용하다고 알려져 있다. Fig. 4에 상용 광 학 소재 및 본 연구소의 연구 결과를 통해 얻어진 유리 소재의 instantaneous Abbe number를 (식5) 계산하 였으며, instantaneous Abbe number가 최대값이 되 는 파장을 산출하여 이의 비교 결과를 도시하였다.

$V^{\prime}(\lambda)=-\frac{1}{2} \frac{n(\lambda)-1}{\nu(\lambda)}, \quad V=V^{\prime}$ 식 5

앞선 Fig. 3과 비교하여 instantaneous Abbe number를 이용하는 경우, 사용 파장에 따른 소재의 선 택이 보다 용이함을 알 수 있으며 소재의 구분이 보다 명확해짐을 확인할 수 있다. 또한, 기존 상용 소재가 커 버하지 못하는 영역 및 결정을 이용하여 렌즈를 제조해 야 하는 영역을 본 연구소의 연구를 통해 제조된 소재를 이용하여 대체 가능함을 확인하였다.

광학설계 관점에서 살펴보면 적용하는 다양한 굴절 률과 분산값을 가지는 적외선 광학소재가 필요하다. 특 히 가장 제약 요소 중 하나는 파장대역에 상관없이 입
사된 빛의 파장대역에 따라 센서 표면에 맺히는 위치 가 다를 경우에 생기는 현상인 수차이다. 원적외선 대역 의 카메라에서는 Achromatic Aberration이 영상의 대 조비를 저하하는 원인이 된다. Fig. 5에서는 (a) 굴절 률 2.6030, 분산값 108.30 (b)굴절률 2.7781, 분산값 160.19 를 가지는 서로 다른 상용 소재의 광학적 특성인 자를 사용하여 EFL (Effective Focal Length) $=50 \mathrm{~mm}$ 단렌즈에 적용 시 발생하는 색수차를 분석하였다. 분산 값과 상관없이 두 저분산 칼코지나이드 소재 모두 상대 적으로 왜곡(Distortion)시 색수차는 미미하나 종방향 색수차(Longitudinal spherical abberations), 비점수 차(astigmatic field curve) 등이 모두 발생하는 것이 확 인되었다. 이는 단렌즈에서 저분산 특성을 가진 조성의 경우에도 다양한 색수차를 포함하고 있음을 의미한다.

Achromatic Lens는 색수차의 영향을 제거하기 위 하여 사용되는 렌즈이다. Achromatic lens는 대개 positive low-index element 및 negative highindex element가 결합된 두 개의 광학 부품으로 구성되 며 achromatic 디자인은 또한 구면수차 최소화에도 사 용된다. Figure 6.에서는 광학소재의 광학적 특성의 상

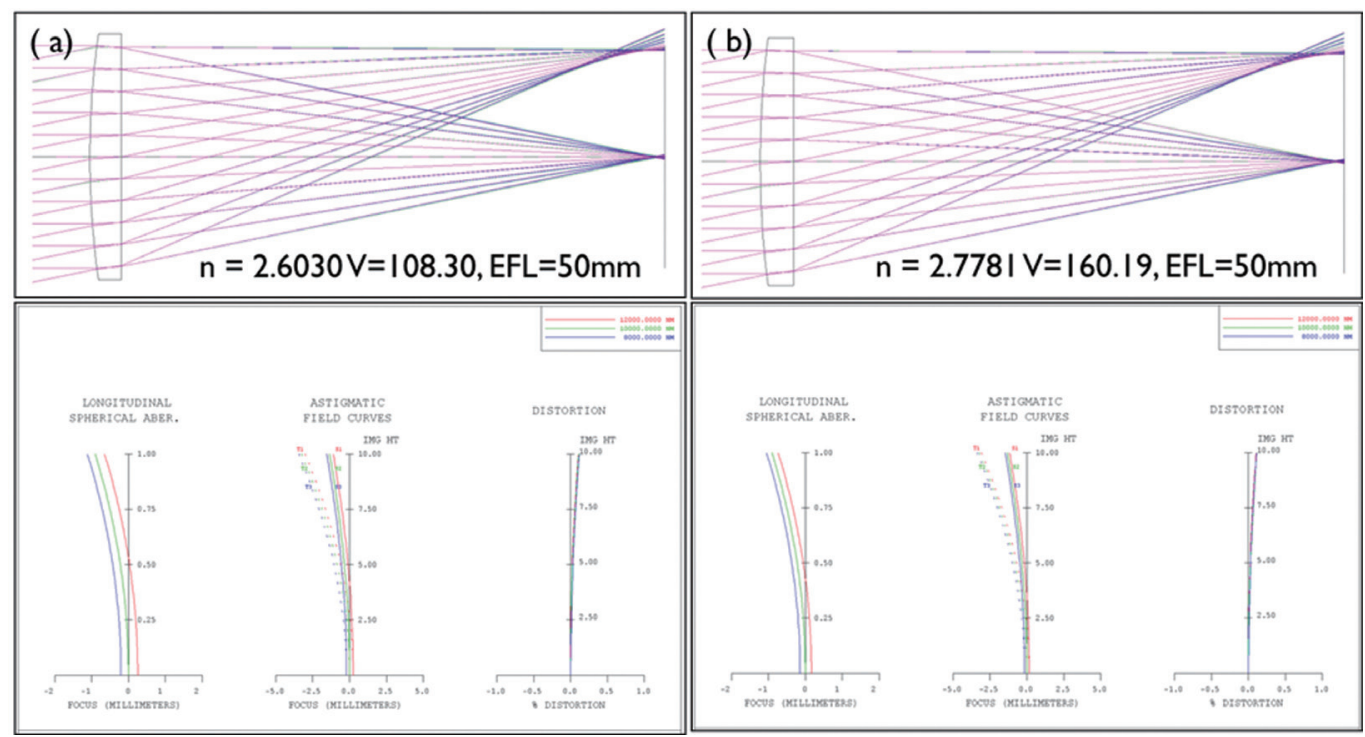

Fig. 5. Effect of chromatic abberations at EFL 50mm using commercial chalcogenide glass with (a) refractive index=2.6030, dispersion=108.30 (b) refractive index $=2.7781$, dispersion=160.19 

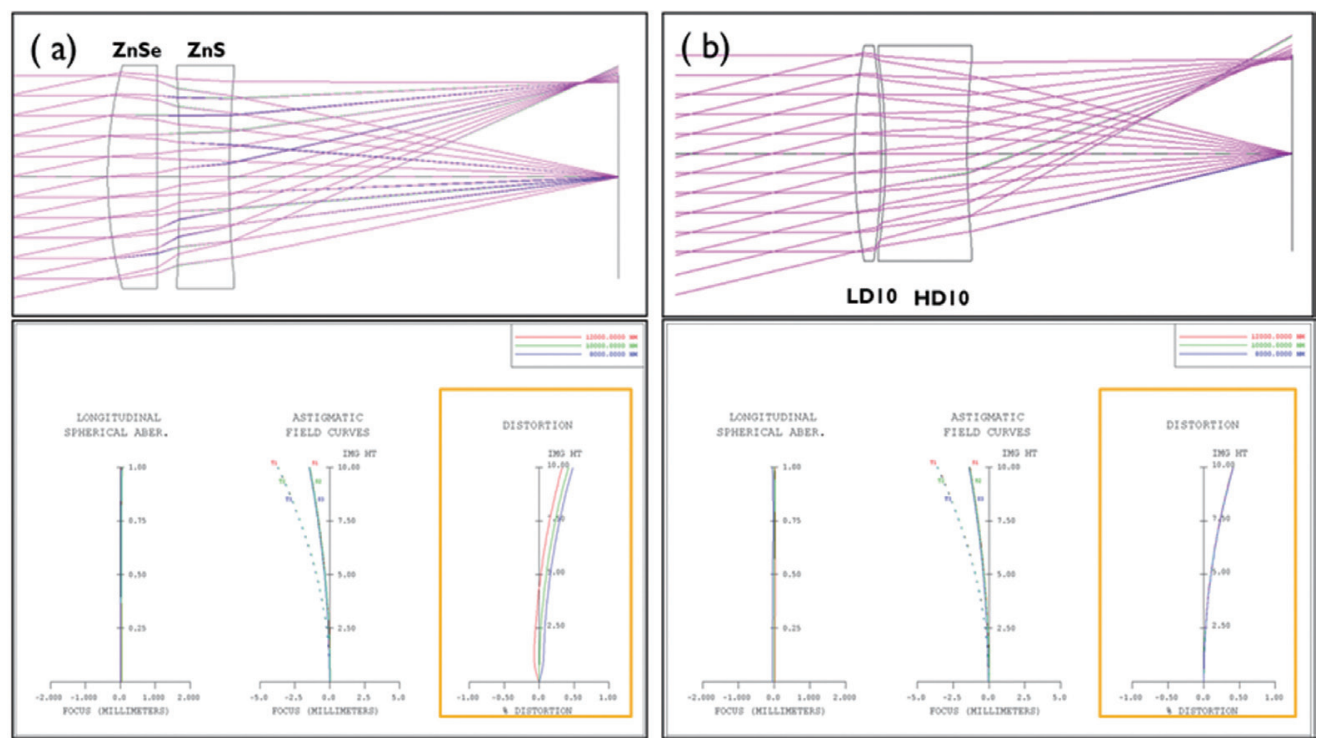

Fig. 6. Effect of chromatic abberations at EFL 50mm using commercial chalcogenide glass with (a) ZnS, ZnSe (b) chalcogenide glass (LD:Low dispersion, HD:high dispersion) from KOPTI

대적 비교를 위하여 동일한 광학설계를 통하여 비교하 여야 하나 제안된 모델로서 정성적 설명을 하고자 한다. 먼저 ZnSe, ZnS 결정질 소재 적용한 모델과 $\mathrm{KOPTI}$ 에 서 개발한 칼코지나이드 유리 소재를 적용한 doublet achromatic lens $(\mathrm{EFL}=50 \mathrm{~mm})$ 의 색수차 발생 경향을 비교 분석하였다. 그 결과, 모두 종방향 색수차는 단렌 즈 대비 개선됨이 확인되었다. 비점수차의 경우 적용 소 재와 상관없이 파장별 색수차가 발생하였으나 왜곡시 결정질 소재 적용 시 발생하는 파장별 색수차 대비 칼코 지나이드 소재 적용 시에는 상대적으로 매우 안정화 되 어있음을 알 수 있다.

\section{3. 결론}

칼코지나이드 유리소재의 경우 $\mathrm{Ge}, \mathrm{As}, \mathrm{Sb}, \mathrm{S}, \mathrm{Se}$ 칼 코겐 원소를 포함하고 있으며 다양한 첨가물에 의한 특 성을 가진 원적외선 투과도를 가지는 유리소재이다. $\mathrm{Ge}-\mathrm{Sb}-\mathrm{Se}$ 기반의 분산값 100 이상 굴절률 2.55 이상 4 종을 개발하였으며 $\mathrm{Ge}-\mathrm{Sb}-\mathrm{Se}$ 기반 조성에 $\mathrm{S}$ 을 첨가함 에 따라 분산값의 조절 통한 고분산 조성 9 종을 개발하 였다. 그중 저분산 $\mathrm{LD} 10$, 고분산 $\mathrm{HD} 10$ 소재를 적용하
여 칼코지나이드 유리소재의 적외선 광학렌즈로써 상대 적 특성을 평가하기 위하여 색수차에 효과를 조사하였 다. 결상 특성 개선을 위해 서로 다른 분산 특성을 가지 는 소재 선정시 instantaneous Abbe number가 최대 값이 되는 파장을 산출하여 결상광학계에서 색수차 분 산에 대한 효과를 비교하기 위하여 doublet achromatic lens 디자인 하였다. $\mathrm{ZnSe}, \mathrm{ZnS}$ 결정질 소재 및 저분 산 고분산 칼코지나이드 소재 광학특성 인자를 적용하여 doublet achromatic lens $(\mathrm{EFL}=50 \mathrm{~mm})$ 색수차 개선 효과를 분석한 결과 칼코지나이드 유리소재가 파장별 색수차 개선 효과가 상대적으로 우수함을 나타내었다.

\section{REFERENCES}

1.X. Zhang, "Chalcogenide glass 'molds' thermal imaging" 16552400, Article, Laser Focus World, 2002.

2. J. Huddleston, "Chalcogenide Aspherical Lenses in IR Imaging" a64333, Article, Photonics Spectra., 2019.

3. M. Friedrichs, "Chalcogenide Glass Molding Advanced Precision in IR Optics" a62080, Article, Photonics Spectra., 2017.

4. L. Zhang, W. Zhou, N. J. Naples, and A. Y. Yi, "Investigation of index change in compression molding 
of $\mathrm{As}_{40} \mathrm{Se}_{50} \mathrm{~S}_{10}$ chalcogenide glass", Appl. Opt., 57 [15] 4245-52 (2018).

5. J. H. Lee, J. H. Choi, J. H. Yi, W. H. Lee, E. S. Lee, Y. G.Choi, "Unravelling interrelations between chemical composition and refractive index dispersion of infrared-transmitting chalcogenide glasses" 8 [1]
15482 Sci. Rep., (2018)

6. H. W. Hoffmann, W. W. Jochs, and G. Westenberger,"Use of the Sellmeier dispersion formula for optical glasses and practical implications," Proc. SPIE., 1780, 303-314 (1992).

\section{최 주 현}

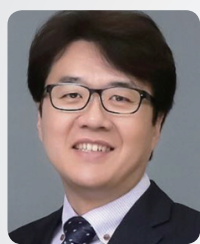

- 2004년 University of California Irvine 박사

- 2009년 University of California Irvine 박사 후 연구원

들 2011년 University of California Los Angeles 연구원

- 2012년 한국광기술원 책임연구원 